\title{
Física e políticas públicas
}

\author{
JOSÉ GOLDEMBERG
}

Ssumindo o RISCO de desapontar os físicos, meus colegas, não falarei
hoje sobre a pesquisa em Física e sua relevância para a compreensão da
natureza, mas sobre a importância da Física para as políticas públicas.

Com relação à pesquisa em Física, poderia apenas repetir aqui os conhecidos exemplos de como a astronomia se desenvolveu em tempos antigos, falar do trabalho de Arquimedes, dos brilhantes trabalhos de Galileu, Newton e Einstein, do entendimento da estrutura de átomos e núcleos, do desenvolvimento da Física Nuclear e de minhas tentativas de contribuir nessa área.

Trabalhei como físico nuclear nos primeiros 25 anos de minha carreira e tentei, até meados da década de 70 , não apenas compreender os avanços atuais na Física mas acrescentar-lhes alguma coisa fazendo experiências com elétrons de energia média (até $100 \mathrm{Mev}$ ). Meu trabalho mais significativo - segundo penso - foi a medição da influência das correntes nucleares (e do magnetismo nuclear) no espalhamento elástico e inelástico de elétrons, o qual, em condições normais, é muito menor do que o espalhamento provocado por cargas nucleares, sendo, por isso, difícil de detectar.

Usando uma técnica especial desenvolvida no Laboratório de Física de Altas Energias da Universidade de Stanford, W.C. Barber e eu medimos o momento magnético de núcleos leves e conseguimos provocar a ressonância gigante que resulta do movimento coletivo de prótons contra nêutrons nos núcleos. Como benefício adicional dessa técnica, tentamos medir o momento magnético do Hélio-4 que, conforme se acreditava, era zero. O resultado foi um novo e importante limite superior no tamanho do elétron - o mais baixo conseguido até aquela data.

Na segunda parte de minha carreira, fui aos poucos empurrado para cargos mais administrativos, e comecei a entender o que a Ciência - e particularmente a Física - podem fazer pelas pessoas. Falando com franqueza, esses aspectos de meu trabalho não tinham para mim grande interesse durante minha primeira fase como físico nuclear, quando minha preocupação dominante era o entendimento dos fenômenos e não a sua aplicação.

Como diretor do Instituto de Física da Universidade de São Paulo por aproximadamente dez anos, na década de 70 , enfrentei a difícil tarefa de justificar, 
dentro da Universidade, a exigência de mais recursos em face de outras demandas. Explicar - fora da Universidade - as razões pelas quais a pesquisa em Física merecia apoio era ainda mais difícil. Isso está parcialmente relacionado ao fato de que o Brasil é um país em desenvolvimento, com prementes necessidades sociais em todas as áreas (educação, saúde, seguridade social, habitação etc.) e não é fácil fazer pesquisa pura ou justificá-la diante de autoridades governamentais muito carentes de recursos. Mais tarde, como ministro de Ciência e Tecnologia e ministro da Educação, vim a entender os dois lados do problema.

Em países desenvolvidos, os governos há muito tempo reconheceram a importância da pesquisa fundamental (particularmente em Física) devido às suas conseqüências óbvias para a guerra e para a paz. Mesmo assim, alguns projetos mais ambiciosos e mais caros como o do superacelerador de feixes em colisão foram abandonados nos Estados Unidos em razão de seus altos custos; a pesquisa em fusão e a estação orbital espacial também enfrentam sérias ameaças de cortes orçamentários. Há duas razões para isso:

- em primeiro lugar, alguns projetos estão ficando tão onerosos que começam a se tornar conspícuos no orçamento do governo, o que não acontecia antes. Como norma prática eu diria que os governos se habituaram à idéia de gastar alguns porcentos do seu orçamento com as universidades (o que é importante para o treinamento de profissionais e cientistas) e talvez até um por cento do orçamento com a pesquisa pura. Se se tentar ir além disso, fatalmente surgem problemas;

- em segundo lugar, os cientistas (e particularmente os físicos) se habituaram à idéia de que seu trabalho deveria ser automaticamente considerado importante e receber financiamento sem muita disputa. A lógica intrínseca da importância da Ciência (e da Física) na expansão das fronteiras do conhecimento parece tão convincente que muitos consideram impróprio e até humilhante ter de justificá-la.

O problema porém é que, quando se trata de financiamentos públicos, as decisões são tomadas por representantes eleitos pelo povo, que têm visões e opiniões muito diversas. É assim que funcionam os sistemas democráticos e muitas vezes nos esquecemos de que os políticos não precisam de um título de doutor nem mesmo para ocupar os cargos públicos mais altos.

Não existe uma fração bem definida do eleitorado capaz de defender a Ciência e a Tecnologia. A Ciência pode ter interesse geral para a nação, mas não é muito relevante em qualquer município específico onde operários, negros (e outras minorias), os muito pobres, funcionários públicos, executivos e fazendeiros são a maioria. Para conseguir a aprovação de projetos caros é preciso explicar como eles estão vinculados a interesses nacionais mais amplos. Isso era, e ainda é, 
relativamente fácil quando se pode invocar a segurança nacional, mas esse não é sempre o caso. Há porém outras áreas nas quais o interesse nacional está em jogo, indo desde a pesquisa do câncer até a agricultura e as células fotovoltaicas. Em países desenvolvidos a pesquisa nessas áreas pode levar à solução de importantes problemas locais e/ou abrir novos mercados para exportação para países menos desenvolvidos.

E qual seria o papel da ciência fundamental (particularmente da Física) em países em desenvolvimento? Muitos cientistas notáveis nasceram e se formaram em países em desenvolvimento e foram capazes de contribuir de modo significativo para o avanço da Ciência. Mais ainda, fizeram isso sem o apoio significativo de seus governos. O talento existe em toda parte. A questão relevante, porém, é outra: existem problemas científicos em países em desenvolvimento que diferem daqueles dos países industrializados? Claramente, a resposta é sim, e a segunda parte de minha carreira foi toda dedicada a provar esse fato.

A partir de meados da década de 70, trabalhei com um reator de pesquisa de 5 Megawatts que foi instalado no campus da Universidade de São Paulo. Em conseqüência, familiarizei-me com reatores nucleares e tive de me envolver nos debates relacionados à energia nuclear como fonte de energia em geral. Passar daí para a compreensão do que estava acontecendo na área da energia em geral foi fácil, uma vez que a crise do petróleo de 1973 gerou a publicação de grande número de bons livros e artigos.

Do ponto de vista de um físico, o conhecimento exigido no que se chama de área da energia é bastante elementar. Contudo, o tema é interdisciplinar por natureza e não apenas a Física, mas também a Engenharia e a Economia estão ligadas de forma íntima quando se trata de analisar em detalhe as fontes convencionais e não-convencionais de energia e de comparar as opções. Além disso, há questões de política - de política energética - nas quais, além do conhecimento tecnológico, se exige bom discernimento e visão política.

É para esta direção que meu trabalho voltou-se na década de 80, quando eu e alguns colegas - Amulya K. N. Reddy, da Índia; Thomas B. Johansson, da Suécia; e Robert H. William, dos Estados Unidos - escrevemos um livro intitulado Energy for a sustainable world, que mais tarde se tornou um componente importante do conceito de desenvolvimento sustentável.

Constatamos que países industrializados basicamente estabilizaram seu consumo de energia a partir de 1980 devido a uma combinação de medidas tomadas depois da crise do petróleo dos anos 70.

O indicador usado para se demonstrar tal fato é a intensidade energética (I), que é a razão entre o total de energia consumida (E) e o produto interno 
bruto (PIB). Há evidências de que, nas duas últimas décadas, a intensidade energética das nações industrializadas vem diminuindo em torno de $2 \%$ ao ano, ou seja, elas estão se tornando energeticamente menos intensivas. Essa é uma descoberta importante porque economistas e planejadores do passado acreditavam que o consumo de energia iria crescer juntamente com o PIB. O fato de que eles podem ser dissociados se deve a:

- melhorias na eficiência do uso de energia graças a melhores técnicas;

- mudanças estruturais nos países que evoluem para uma economia pósindustrial.

No entanto, em países em desenvolvimento, a intensidade energética está aumentando, uma vez que essas nações estão em estágios mais incipientes de desenvolvimento. É fácil ver que combinando esse fato com uma população crescente, os países em desenvolvimento estariam propensos a dominar o cenário mundial no que se refere ao consumo de energia no começo do próximo século. Isso criará muita tensão no sistema internacional e apresentará riscos de segurança ao acesso às cada vez mais escassas reservas de energia.

Nossa proposta - que despertou muita atenção - foi a de que no caso dos países em desenvolvimento não se chega à solução através da conservação de energia, visto que o consumo de energia per capita é muito pequeno, mas através de um pula-sela tecnológico (isto é, um salto para a frente, como na brincadeira das crianças). O crescimento do consumo de energia em países em desenvolvimento é inevitável dada a necessidade de se construir infra-estruturas industrial, de transporte e de desenvolvimento urbano. Uma vez que os países em desenvolvimento estão crescendo, o uso extensivo de melhores tecnologias incluindo dispositivos energeticamente eficientes - deve ser incorporado logo no início do processo de desenvolvimento e não como adequação retroativa, como acontece nos países industrializados. É por isso que os países em desenvolvimento são palcos importantes para a inovação e para saltos qualitativos, especialmente nas indústrias de materiais básicos de alta intensidade energética (aço, produtos químicos, cimento), ao passo que a demanda de energia já atingiu a saturação em países industrializados.

É de fato surpreendente a rapidez com que se adotam e difundem técnicas inovadoras e de ponta em países em desenvolvimento que se modernizam: quando aldeias da Índia são eletrificadas, a iluminação é fornecida por lâmpadas fluorescentes em vez das antigas e ineficientes lâmpadas incandescentes. A TV em branco e preto é coisa do passado até mesmo nas remotas áreas da Amazônia e a TV a cabo aparece em muitos locais. O mesmo vem acontecendo com o telefone celular, que está levando ao abandono do aparelho conectado por fios em países como as Filipinas ou o Vietnã. 
Com base nesses exemplos de saltos qualitativos bem-sucedidos, eu e meus colegas calculamos a energia necessária para tornar acessíveis a toda população de países em desenvolvimento as amenidades à disposição da população dos países da Europa Ocidental em meados da década de 70, tais como iluminação, refrigeração, automóveis etc., usando a melhor tecnologia disponível. O resultado surpreendente foi que a energia necessária é aproximadamente a mesma que se consome hoje: em outras palavras, o emprego maciço de tecnologia moderna também poderia estabilizar o consumo de energia em países em desenvolvimento.

Por essa razão nosso trabalho tornou-se um dos componentes básicos do Relatório da Comissão Brundtland, Our common future (Nosso futuro comum), que preparou o caminho para a Conferência das Nações Unidas sobre MeioAmbiente e Desenvolvimento no Rio de Janeiro em 1992.

O caminho para a sustentabilidade consiste na abordagem geral de futuros problemas globais e há inúmeras oportunidades para a Ciência (particularmente para a Física) indicar os detalhes sobre como proceder. Em todos os casos é preciso resolver problemas técnicos assim como fazer avaliações criteriosas.

Por exemplo, uma área que recentemente se tornou importante é a preocupação crescente com as mudanças climáticas e o aquecimento global atribuíveis a atividades antropogênicas, como a queima de combustíveis fósseis. Os governos precisam decidir o que fazer a respeito desses problemas e os conselhos de cientistas são ansiosamente procurados nessas ocasiões. Tais demandas esclarecem o papel da ciência aos olhos do governo e ajudam a abrir os cofres até mesmo dos governantes mais ávaros.

Física (e Ciência em geral) e Políticas Públicas estão portanto intimamente interligadas e meu treinamento de físico provou ser um trunfo em minhas atividades em cargos administrativos do governo.

Na homenagem que me dispensa, a Universidade de Tel Aviv parece reconhecer essa relação e espero que abra espaço nos seus programas de treinamento e pesquisa com o objetivo de preparar a geração mais jovem para o estreitamento da relação entre a Física e as Políticas Públicas.

José Goldemberg, físico, é professor honorário do Instituto de Estudos Avançados da Universidade de São Paulo.

Palestra feita pelo autor na Universidade de Tel Aviv, Israel, em 26 de maio de 1994, na inauguração da Cadeira José Goldemberg de Física Atmosférica.

Tradução de Almiro Pisetta. O original em inglês - Physics and public policy - encontra-se à disposição do leitor no IEA-USP para eventual consulta. 